\title{
The Robust Learning Model (RLM): A Comprehensive Approach To A New Online University
}

Yoram Neumann, TUI University, California, USA Edith F. Neumann, TUI University, California, USA

\begin{abstract}
This paper outlines the components of the Robust Learning Model (RLM) as a conceptual framework for creating a new online university offering numerous degree programs at all degree levels. The RLM is a multi-factorial model based on the basic belief that successful learning outcomes depend on multiple factors employed together in a holistic approach. This comprehensive approach was fully implemented and resulted in quality learning at all degree levels, affordable tuition, and accountability.
\end{abstract}

Keywords: online learning, online university, learning effectiveness, accountability, assessment

\section{INTRODUCTION}

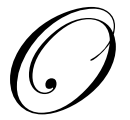

nline teaching and learning became prevalent in the U.S. and in the world, and became one of the challenges of institutions of higher learning in terms of faculty participation, pedagogy, technology and organizational adaptation. There are several models that have been implemented in the online teaching and learning environment. Various traditional brick and mortar universities are experimenting with a hybrid model with some courses taught online and others on site (traditionally). Few institutions exist that are pre-planned to offer entire degrees online and also develop a built-in infrastructure that solely focuses on the online environment. Usually, institutions transferred courses that were taught in the face-to-face modality to an online learning modality with varying degrees of success. One of the gaps in the existing e-learning literature is the area of on-line university planning and administration. Our model (RLM) was developed and implemented with specific administration structure for a new online university offering undergraduate, masters and doctoral degrees completely online.

\section{THE THEORETICAL DIMENSION}

In 1984, the authors committed themselves to a long-term program of research in higher education and its improvement at the university/college level. Together, they have conducted several research projects on college/university students and learning, faculty vitality and performance, and college/university presidents and their impact on their institutions.

In studying student success and learning (Neumann and Neumann 1989,1993, 1995; Neumann, Neumann, and Reichel, 1990), several factors related to the quality of learning experience emerged as determinants of many facets of students' academic performance and related outcomes (retention, graduation, satisfaction, and commitment toward their university). The four major predictors of student learning outcomes were: student engagement and involvement in a variety of activities aimed at different cognitive domains of learning; student-faculty contact, including faculty helpfulness as well as the accessibility of faculty manifested through the immediacy of feedback and concerns for students and their problems; degree program-related factors including the integration and relevance of the various required and elective courses as well as the quality of teaching focused on student learning and the quality of academic advising; and learning opportunities beyond traditional courses consisting of possibilities to engage in self-directed learning and address critical issues in the course. 


\section{THE PRACTICE DIMENSION}

Parallel to their interest in advancing policy-based knowledge in higher education and also starting in 1984, the authors, while in leadership positions in several institutions of higher learning, were involved in pioneering learner-centered distance learning programs (stage one) and online learning (stage two). Throughout their leadership experience in distance and online learning, they have developed a unique vision for a new online university where all functions (academic and administrative) are directly linked to one learning model. The model was named the Robust Learning Model (RLM), and it was built on quality standards derived from the authors own research that later implicitly became part on the best practices in online learning recognized nationally and internationally. The initial model was developed in 1994 and was first presented in the international conference of the Academy of Business Administration in 1996 (Athens, Greece).

\section{THE ROBUST LEARNING MODEL (RLM) AND ITS COMPONENTS}

\section{The Robust Learning Model was the basis of the development of the on-line university.}

The RLM is a multi-factorial model based on the basic belief that successful learning outcomes depend on multiple factors employed together in a holistic approach.

Figure 1- The Robust Learning Model Conceptual Framework

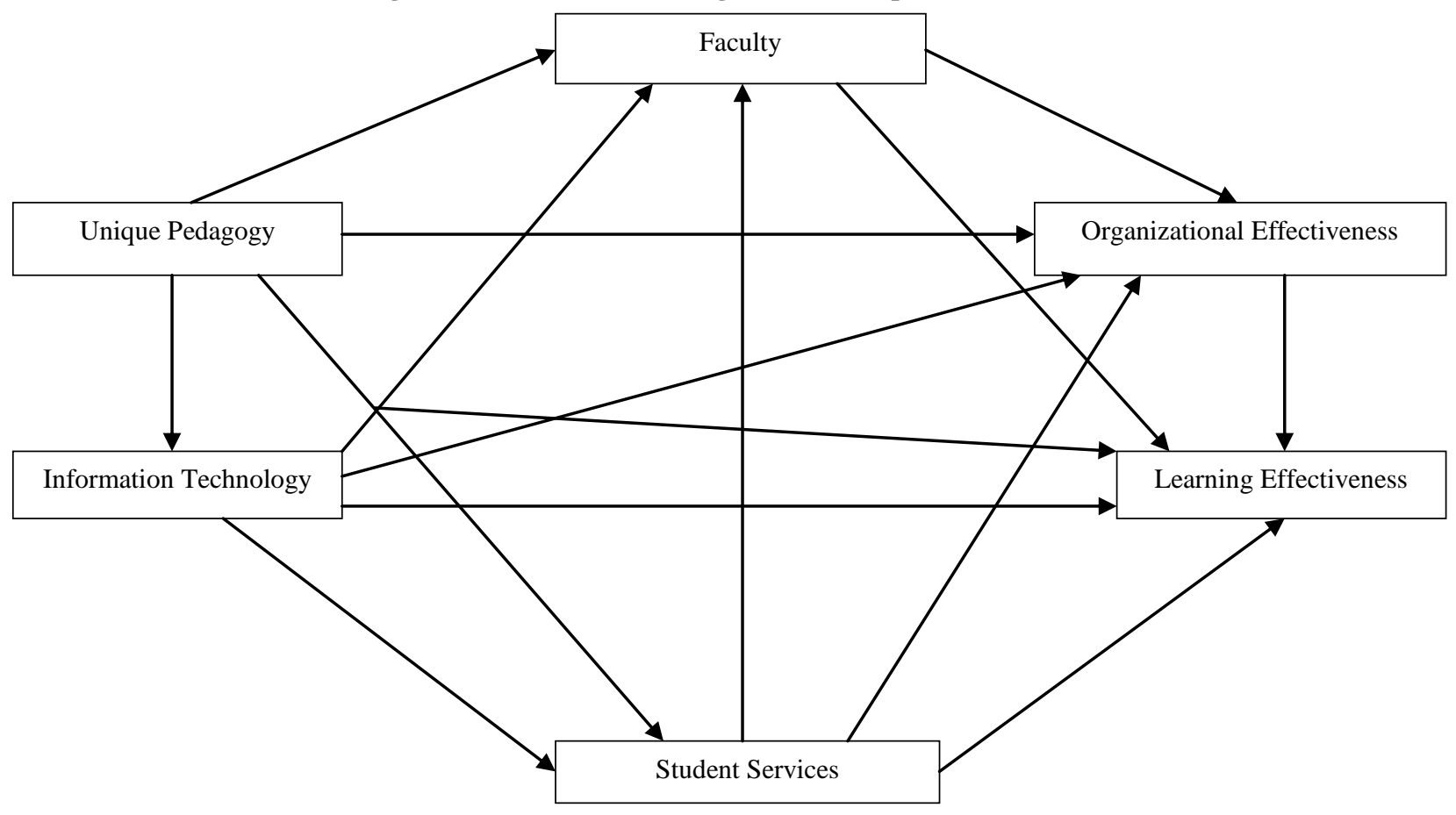

Figure 1 presents the Robust Learning Model.

\section{The RLM was developed adhering to the following standards:}

- $\quad$ Comprehensive to enable systematic applications to all degree programs.

- $\quad$ Widespread relevance for many groups of learners including adult and mobile learners.

- $\quad$ Built in mechanism for accountability, transparency, affordability, and quality assurance.

- $\quad$ Budget and resource allocation plan designed to meet the needs of the various components of the model based on projected enrollment growth and pre-defined quality improvements. 
- $\quad$ Provides Scalability in all activities.

- $\quad$ Results in verifiable attainment of learning outcomes of students for each degree program.

\section{Each component of the RLM is interconnected as seen in Figure 1.}

Each component of the RLM contributes to the two major Capacity Outcome Measures of Educational Effectiveness: Student Learning Outcomes (SLO) and Organizational Effectiveness.

Pedagogy and Delivery of the programs was one of the basic factors developed in the RLM. During the planning phase, the specified learning outcomes/objectives for five different levels (university, college, degree program, course, and module) were developed and focused on consistency across programs and courses, alignment of mission and goals of the university with those of the program, and being hierarchical and exhaustive at a rigor commensurate with the degree level.

The courses were developed as module-based courses across all degree programs; each course consists of substantive modules and a final evaluative/integrative module.

Each substantive module includes background readings and materials written by the professor; the background component includes multimedia presentation and web-based library references. The background materials are aimed at providing the students with the body of knowledge they will need to work on the course assignments.

The course assignments include case analysis, which cover the learning objectives of the module and are instrumental in developing analytic, argumentation, writing, multi-perspective and critical thinking competencies.

The implication project (Session Long Project) is focused on the application of the course/module body of knowledge and related independent research to a problem relevant to the student's own experience.

In order to allow student- faculty, student to student interaction and engagement, a threaded discussion component was developed, and it is intended to elicit discussion between faculty and students and among the student group with the specific goals for students to engage other students in a meaningful asynchronous exchange in response to a provocative or relevant issue statement by the faculty.

Faculty members then stimulate further discussion and interaction among the student group while clarifying unclear topics as needed. All modular components are consistently applied to each program and course.

Information Technology is the backbone of the RLM; the strategy was to develop a well thought-out webcentric integrative technology. The IT system was developed specifically to support the university's pedagogical approach and the student learning-centered environment created by the RLM. The Information Technology capability was built in stages and in a continuous development mode as additional needs arise. From the inception of the university, the IT department served as a conduit for the development of the university on the foundation of the Robust Learning Model. The IT solution provides administration and faculty the ability to easily manage students' records. In addition, students are able to manage their own records through the system. Students are able to submit their assignments in a secured environment, while faculty is able to grade the papers and provide feedback through the system. The threaded discussions are also posted through the same system.

The IT integrative system creates and manages students' degree plans, transfer credits, course waivers, prerequisites, and course replacements. Alumni are able to contact the university, as well as administrators and staff, to manage alumni records. The system integrates finance and financial aid records for students and administration, and allows administrative users to manage a complete student record, from the initial student's application, enrollments, transcripts, grade reports, statuses and more, up until graduation. For faculty, the system is incredibly important as it allows review of students' assignments and enables them to provide feedback to students. The IT system also allows faculty assessment and course assessment by students, and peer review for promotion. The system also allows for faculty training. 
What is unique in the integrated system is that it allows faculty committees to assess course quality as well as student learning outcomes (both the input and the outcome of the students' quality of learning). Finally, since all of the above-mentioned activities are archived, including students' work and assignments, as well as faculty feedback and all assessment activities by faculty, the system provides the university with a unique transparency and the appropriate database that may be used for comparative studies and long term learning outcomes assessment activities. In addition, the system has the capacity to provide the various reports needed for administrators, staff and faculty.

Another crucial component of the RLM is Faculty. All faculty members (full time and part time) possess doctoral or professional terminal degrees; this requirement enhances the capacity to provide high quality education.

The standards of conduct for faculty are:

- $\quad$ Responsiveness (24-hour turnaround on email and 72-hour turnaround for grading assignments).

- $\quad$ Flexibility with students on course and assignment deadlines.

- $\quad$ Constructive and supportive feedback and communications with students.

- $\quad$ Faculty roles and workloads at the university are designed to serve students effectively, promote student centeredness and measurable learning outcomes, in addition to providing a mechanism for sustainable quality assurance as the university grows.

- $\quad$ Serving the institution through committee work, as well as course development and maintenance.

- $\quad$ Providing timely and constructive feedback (including text-based and audio) on students' assignments for each module.

- $\quad$ Grading of all assignments and submitting final grades.

- $\quad$ Engaging students in meaningful learning through discussions with their peers and their core faculty.

Another very important component of the RLM is Student Services; these services include the office of the registrar, the IT department, the recruitment center, advisement center, finance department, library services and shipment department.

Looking at the RLM as a comprehensive model to develop a new university, and as we assess the capacity of the university and its success, the first area to examine is whether there is organizational effectiveness. Organizational Effectiveness is a multivariate concept that includes transparency and accountability, productivity gains of the RLM model, and students' learning effectiveness.

The factors we found that contribute to the transparency and accountability of the university are:

- $\quad$ Archived assignments in the course management system.

- $\quad$ Course $\mathrm{CD} /$ Links for asynchronous instruction.

- $\quad$ Archived live conferences.

- Archived progress in dissertation proposals.

- $\quad$ Archived progress in dissertation process.

- $\quad$ Final dissertation for PhD students.

- $\quad$ Archived assessment processes by faculty committees of the quality of the courses

- $\quad$ Archived assessment of faculty feedback to students

- $\quad$ Archived student assessment of course and faculty

The RLM Productivity Gain is an important factor in assessing the success of any implemented model.

Efficient and effective use of resources is enabled by the Robust Learning Model and its Technology (Productivity Gain 1).

Effective use of time by faculty, staff, and administration are enabled by the model and its focus on learning-centered, learning-supported, and student-centered activities (Productivity Gain 2). 
The byproduct of the above productivity gains is an effective and efficient cost structure for the university, which in turn facilitates affordable tuition.

As a result, access to higher education for underserved populations (Productivity Gain 3) is enabled due to the affordable tuition, user-friendly technology and the quality and flexibility of services.

The aforementioned productivity gains lead to additional gains of the model and these are: high levels of satisfaction with all facets of the Robust Learning Model and the university expressed by students alumni and stakeholders (Productivity Gain 4), and high levels of commitment to the organization by its students and alumni enabling the recruitment of new students through referrals and word-of-mouth (Productivity Gain 5).

Figure 2 presents the alignment of mission, goals, and learning objectives. The outcome variable of Students Learning Effectiveness is the most important outcome measure for a university's quality. From the early design of the RLM, the goal was that a robust assessment of educational effectiveness program should be developed for all degree programs. The following steps were taken in order to ensure educational effectiveness: reviewing, assessing through benchmarking, and improving the common body of knowledge for each degree program; developing university mission and learning objectives and outcomes compatible with the RLM; developing learning outcomes for each degree program, course and module offered that reflect the benchmarking results for the common body of knowledge for that degree program.

\section{Alignment of Missions, Goals, \& Learning Objectives Figure 2}

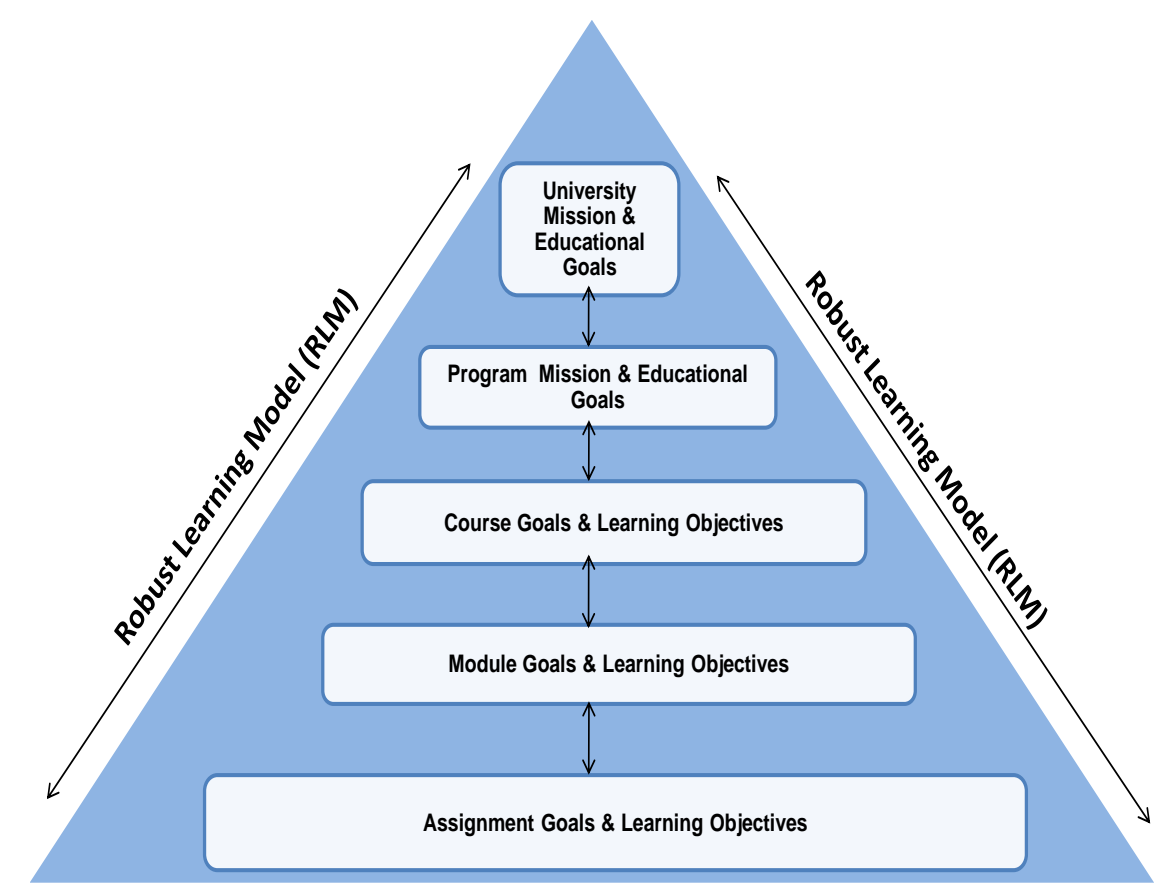

Students' work is assessed for direct learning outcomes within the RLM. In order to ensure students' learning outcomes, course evaluation allows for the assessment and improvement of faculty teaching effectiveness. By reviewing the feedback provided to students by faculty on case assignments and session long projects, as well as the quality of faculty participation in course threaded discussions, assessment and improvement of faculty teaching is facilitated. Faculty teaching effectiveness is assessed by the course evaluation and teaching improvement occurs following the evaluation. 
Figure 3

Evidence-Based Teaching Effectiveness and the Contiguous Improvement Process

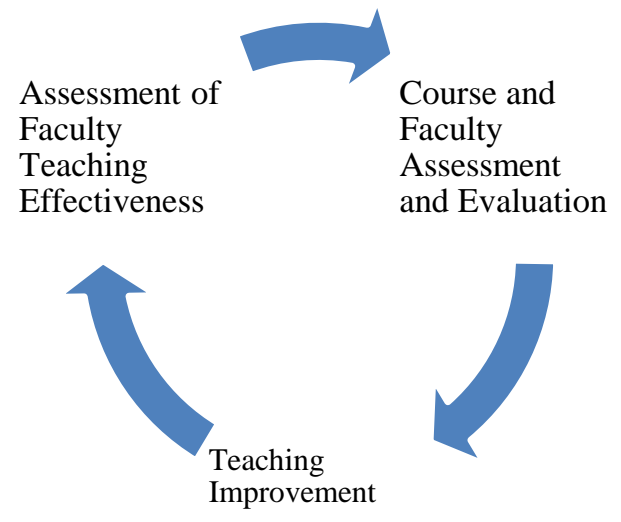

The evidence-based teaching effectiveness and the contiguous improvement process are exhibited in Figure 3. Teaching evaluations must be collected from several sources in order to be triangulated. In addition to course and faculty assessment at the end of each course, surveying students for their satisfaction with the various aspects of the quality of their learning experience a is very important during their studies as well as conducting exit surveys at the end of their studies, including surveys of alumni to solicit their feedback on the various aspects of the academic program they have completed. Measuring alumni opinions of the academic programs and the programs' impact on their career provides information about the long term impact of the teaching and learning process. Consistently obtaining the aforementioned performance indicators; disseminating them to faculty, staff, and administration; discussing them regularly in academic and general forums; and using the results in continuous improvement planning and implementation has a great impact on the university continuous improvement aspect.

To ensure the educational effectiveness of the PhD programs, the common body of knowledge for each of the $\mathrm{PhD}$ programs was examined, benchmarked, and improved; this process will be repeated periodically. The courses' assessment findings are implemented in each of the $\mathrm{PhD}$ programs, resulting in: more rigorous syllabi for all $\mathrm{PhD}$ courses, benchmarked improvement of course content, more demanding and consistent session-long projects, peer-reviewed scholarly articles as the cornerstone for case assignments and improved faculty-student integrated threaded discussions. Highly demanding, comprehensive examinations were established in each of the $\mathrm{PhD}$ programs. The addition of a dissertation prospectus as a prerequisite to the development of the full research proposal has enhanced the quality control of the $\mathrm{PhD}$ process. A quarterly review takes place of the progress of each $\mathrm{PhD}$ student at the proposal and dissertation stage, along with a quarterly review of the performance of each dissertation chair. Attention has been given to improving the quality of dissertation mentors, resulting in attracting doctoral-qualified experts with proven track records of publications in refereed journals in the areas of the proposed dissertations. To effectively address capacity issues, a faculty deployment plan has been developed and enrollments in each of the $\mathrm{PhD}$ programs have been capped and then reduced. Quality control processes were used to establish "best practices" for the university which are consistent with other PhD-granting institutions; this was accomplished through benchmarking of the $\mathrm{PhD}$ curricula, the admission standards, degree requirements and syllabi.

In order to assess the effectiveness of student learning, collection and analysis of a large quantity of data must take place. A course management system archive contains the data needed for faculty assessment of student direct learning for all degree programs by faculty committees. Retention data and reports are also available on the course management system, which are then assessed by the Academic Council. To assess the alignment of learning outcomes and objectives at the program level, course level, and module level for each degree program, Master Course CDs and/or web links are available for faculty committees to review. These committees also collect and analyze benchmarking data used for determining the common body of knowledge for each degree program. Teaching and course evaluations are collected by the robust technology and analyzed by Institutional Research. Exit questionnaires are collected by the Registrar and analyzed by Institutional Research; Student satisfaction surveys are 
administered and also analyzed by Institutional Research. In the PhD program, Live Conferencing archives contain the data needed for faculty committees to assess the students' direct learning in synchronous delivery.

To assess the institution's capacity for learning, beginning with faculty capacity, many practices have been put into place. First, the institution ensures that faculty members possess the appropriate degrees and expertise in the area of teaching. Deviations from the 72-hour rule for feedback and grading of assignments are documented and analyzed, as is the frequency of faculty participation in the threaded discussions, which pertains to student-faculty interaction. For PhD students, documenting and analyzing deviations from the two-week rule for providing detailed feedback on drafts of their dissertation proposals and dissertations is necessary to ensure that students can progress in a timely manner. If students have any complaints regarding a lack of timely response by faculty to their e-mails (the 24-hour rule), the incidents are documented and analyzed.

Another essential aspect of the capacity for learning is the presence of capable and efficient Student Services, which include Information Technology, Registrar and Student Services, Advisement Center, Finance Department, Library Services, Shipment Department, Faculty and Administration. Student complaints regarding lack of timely response to their e-mail or any other request (the 24-hour rule) are documented and analyzed.

Infrastructure is also crucial to the institution's capacity for learning and the network infrastructure and IT hardware and software of the university are regularly reviewed, analyzed and augmented to meet scalability needs and improve the system. The space the university needs to accommodate the RLM implementation of additional faculty and staff members is also reviewed and analyzed. Underlying all of this is a solid financial base.

Table 1

The Detailed Components of the Robust Learning Model

\begin{tabular}{|c|c|}
\hline Pedagogy & Courses \\
\hline $\begin{array}{l}\text { Module-based } \\
\text { Problem-based } \\
\text { Application-oriented } \\
\text { Threaded Discussion collaboration } \\
\text { Comprehensive feedback } \\
\text { Learner-centered } \\
\text { Asynchronous and Synchronous } \\
\text { Multimedia }\end{array}$ & $\begin{array}{l}\text { Quality content } \\
\text { Written Case and Session-long assignments } \\
\text { Clear learning objectives } \\
\text { Up-to-date reading material } \\
\text { Comprehensive syllabi } \\
\text { Significance of the course for the program } \\
\text { Clarity of the course presentation } \\
\text { Rigor at the degree level }\end{array}$ \\
\hline Technology & Faculty \\
\hline $\begin{array}{l}\text { Web-centric integrative } \\
\text { Homegrown } \\
\text { Secure } \\
\text { High capacity and speed } \\
\text { One-stop Student Management System } \\
\text { Archiving of all conferences and meetings }\end{array}$ & $\begin{array}{l}\text { Doctoral-prepared } \\
\text { Should design and maintain all courses } \\
\text { Onsite faculty, to develop academic community } \\
\text { Conduct research individually and with PhD students } \\
\text { Provide timely and constructive feedback } \\
\text { Grade all assignments and submit final grades } \\
\text { Engage students in meaningful learning } \\
\text { Capacity matrix for enrollment growth }\end{array}$ \\
\hline Student Services & Organizational Effectiveness \& Learning Effectiveness \\
\hline $\begin{array}{l}\text { All Student Services Systems are integrated } \\
\text { Students' communication addressed within } 24 \text { hours } \\
\text { Course production with Quality Assurance } \\
\text { Synchronous learning at PhD level } \\
\text { Web-based } 24 / 7 \text { accessible online library } \\
\text { Pre-admission advisement } \\
\text { Post-admission advisement } \\
\text { Retention activities } \\
\text { Flexibility } \\
\text { Alumni Support }\end{array}$ & $\begin{array}{l}\text { Make effective decisions at the university, division and unit } \\
\text { levels } \\
\text { Monitor growth and plan resources } \\
\text { Communicate effectively within the organization } \\
\text { Ensure student retention and graduation } \\
\text { Ensure faculty and staff commitment } \\
\text { Capability to assess student learning } \\
\text { Develop a fully-integrated management system } \\
\text { Transparency and accountability } \\
\text { Effective and efficient use of resources } \\
\text { Learner-centered environment }\end{array}$ \\
\hline
\end{tabular}


To collect and analyze the data needed for capacity assessment, the information technology management system archives contain all of the data needed for assessing the adherence to the 72-hour rule for grading and feedback as well as the frequency of faculty-student interaction through the use of threaded discussions. Complaints about the deviation from the 24-hour rule on e-mail responses by any academic or non-academic unit at the institution are collected and archived by the management and are analyzed by Institutional Research. In addition, the financial statements and audits represent strong financial capacity. The detailed components of the RLM are outlined in Table 1.

\section{The RLM provides the capacity for the measurement of Learning Effectiveness -Student Learning Outcomes (SLO)}

The RLM enables the university to develop and improve the learning outcomes or what the learners expected to achieve by attending the University. For each degree program offered by the University, the RLM directs the institution to: ensure that all learning outcomes are covered; reflect on the benchmarking results for the common body of knowledge for each degree program; design the curricula and courses for each degree program to cover all its learning outcomes; review, assess through benchmarking and improving the common body of knowledge for each degree program; and include the degree program learning outcomes in the university publications. University.

Developing and improving the learning outcomes or what the learners expected to achieve by attending the

Developing and improving the learning outcomes for each degree program offered by:

- $\quad$ Covering the learning outcomes

- $\quad$ Reflecting on the benchmarking results for the common body of knowledge for that degree program

- $\quad$ Designing the curricula and courses for each degree program to cover all its learning outcomes

- Reviewing, assessing through benchmarking, and improving the common body of knowledge for each degree

- $\quad$ Including the degree program learning outcomes in the university publications

\section{Program Learning Outcomes:}

- $\quad$ Focus on what students will learn, rather than on what faculty will teach.

- $\quad$ Describe how students can demonstrate that they have developed the knowledge, skills, and values that the faculty wants them to learn.

- $\quad$ Should be widely distributed - in the catalog, on the Web, and specifically on the syllabi.

The curriculum and course planning should be developed so that students experience a cohesiveness of the CBK in curriculum and courses.

Figure 4 outlines the assessment of student learning. The first step is to develop learning objectives/outcomes for each course in a degree program so that the combination of all courses required for graduation will cover all the learning outcomes for the specific degree program.

The next step is to ensure that course and module assignments should guarantee the attainment of the course and module objectives/outcomes. Every session/semester, each course must be reviewed for currency; the learning objectives/outcomes should be revisited, along with the content and assignments. 
Figure 4

\section{Assessment of Student Learning}

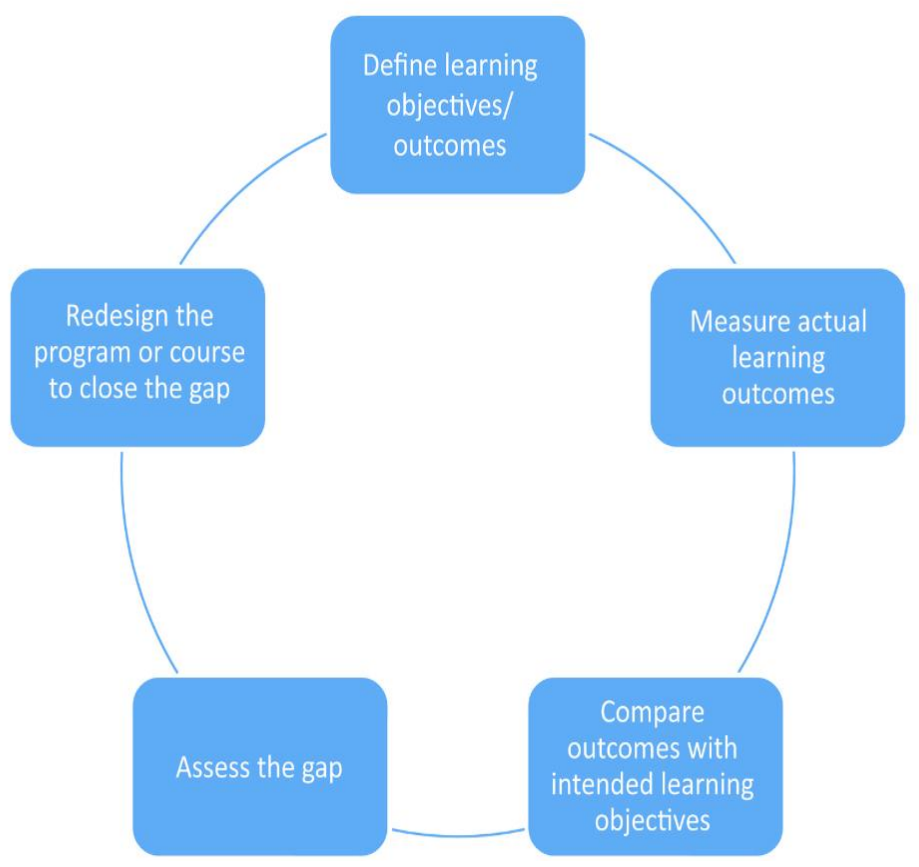

In order to assess Student Learning Outcomes, evaluations of the learning as demonstrated by the course case assignments, session-long projects and threaded discussions are reviewed for course improvement. Students' self-reflective papers, which are required in the last module of each course, are also used to assess and improve the direct learning in each course within the program. At the end of each program, the capstone course also provides a means of gauging and revising the direct learning taking place in the particular program. Once these assessments have taken place, the findings can be aligned with the learning outcomes for the program by performing gap analysis and revising the curricula and the program with the results in mind. At this point, the results of the multiple methods of assessing direct learning are discussed in the appropriate forums and changes are recommended to the appropriate Dean and the Provost for implementation. Course evaluations for each course offered allow for assessing and improving faculty teaching effectiveness. Additionally assessed is the feedback that a faculty provides to students on case assignments and session-long projects, as well as the quality of faculty participation in course threaded discussions. All students are surveyed for their satisfaction with the various aspects of, and input regarding, the quality of their learning experience. Exit surveys of students including all graduates solicit their feedback on various aspects of the academic program. Lastly, alumni opinions of academic programs and the program's impact on their career are measured and reviewed.

\section{SUMMARY OF THE RLM AND ITS RELEVANCE}

The RLM is particularly important in the context of the development of a variety of organizational structures for institutions of higher learning and governance. The RLM has a built-in capacity for, and adopted the best educational practices in, structuring curricula, courses and assignments, including supporting student engagement to stimulate student involvement, and it enhances the conditions for learning and individual development. Assessment of student learning outcomes leads to providing feedback which guides further improvements in policy and practices. 
In the RLM, the decisions are made by both the unit members and leaders and the hierarchical structures can lead the institution with their strategic decisions. The power in the model is distributed among all functions of the organization. The model preserves faculty participation, academic freedom and stakeholder participation. The RLM provides capacities for scalability, the development of a highly effective and efficient institution of higher learning, and for built-in assessment of student learning outcomes.

\section{AUTHOR INFORMATION}

Yoram Neumann, ( $\mathrm{PhD}$ Cornell University), MBA, is the Founder, Executive Chairman, and Chairman of the Board of TUI University. From 1998 to 2009, he served as the President and CEO of the university. TUI University offers Bachelors, Masters, and PhD degree programs in Business Administration, Health Sciences, Education, and Information Systems. Previously, Dr. Neumann served as the Executive Vice President and Vice President for Academic Affairs and Dean of the College of Business and Public Administration at California State University, Dominguez Hills. Professor Yoram Neumann also served as Research Professor and the Director of the Graduate Program in Technology Strategy and Policy at Boston University and Dean of the Faculty of Humanities and Social Sciences at Ben-Gurion University.

Edith Neumann, Ph.D. (Boston University), M.Sc., R.N., is the President, TUI Institute of Learning and the Chair, Academic Committee of the Board of TUI University. Dr. Edith Neumann is the former Vice President for Academic Affairs and is the founding Dean of the Colleges of Education and Health Sciences. Dr. Neumann served as Dean of the School of Health and Director of the Center for Policy Research and Evaluation at California State University, and on the faculty of Boston University and Ben-Gurion University.

\section{REFERENCES}

1. Neumann, Y. \& Neumann, E.F. (1989). Predicting juniors' and seniors' persistence and attrition: A quality of learning experience approach. Journal of Experimental Education, 57 (2), 129-140.

2. Neumann, Y. \& Neumann, E.F. (1993). Quality of learning experience and students' college outcomes. International Journal of Educational Management, 7 (1), 4-10.

3. Neumann, Y. \& Neumann, E.F. (1995). Quality learning teams: Improving student retention, performance, and satisfaction. In A.M. Hoffman and D.J. Julius (Eds.), Total quality management: Implications for higher education (pp. 246-266). Maryville, MO: Prescott Publishing Company.

4. Neumann, Y., Neumann, E.F., \& Reichel, A. (1990). Determinants and consequences of students' burnout in universities. The Journal of Higher Education, 61 (1), 20-31. 